\title{
Hypertrophic gastric folds caused by metastatic prostate adenocarcinoma
}

The stomach represents an unusual site for metastatic lesions, and secondary tumors mimicking diffusely infiltrating primary gastric cancer are exceptionally rare [1]. With respect to prostate cancer, metastases to the upper gastrointestinal tract have only infrequently been described, and published data are mainly confined to single case reports [2-4].

A 69-year-old man diagnosed with prostate cancer 8 years earlier underwent upper endoscopy for unspecific abdominal discomfort. Inspection of the stomach revealed diffuse hypertrophic gastric folds within the upper third of the stomach ( Fig. 1). Upon histological examination, the gastric oxyntic-type mucosa was found to be diffusely infiltrated by polymorphous cancer cells with enlarged irregular nuclei and cytoplasmic vacuolization ( Fig.2). The cancer cells were immunoreactive for prostate-specific antigen (PSA) ( Fig.3a) and androgen receptor ( Fig.3b). The MIB-1 proliferation index was $25 \%$.

Within the gastrointestinal tract, metastatic cancer is most often encountered as a solitary lesion resembling a submucosal tumor with or without a central depression and/or ("volcano"-like) mucosal ulceration. The lesions are typically located in the middle or upper third of the stomach [1]. Diffuse thickening of gastric folds and/or linitis plastica-like changes due to a secondary tumor are exceedingly rare and have, so far, mainly been reported for metastatic breast cancer [5]. To the best of our knowledge, metastatic disease due to prostate cancer has only once before been reported as a cause of hypertrophic gastric folds [4].

Differential diagnoses mainly include: Ménétrier's disease, a rare hyperproliferative protein-losing gastropathy; lymphocytic gastritis, a rare variant of gastritis which is mainly associated with Helicobacter pylori infection; gastric lymphoma; and primary gastric cancer.

In conclusion, we present a case of hypertrophic gastric folds caused by metastatic prostate adenocarcinoma. Endoscopists should consider gastric metastasis in the work-up of patients with known malignancies who present with hypertrophic gastric folds.

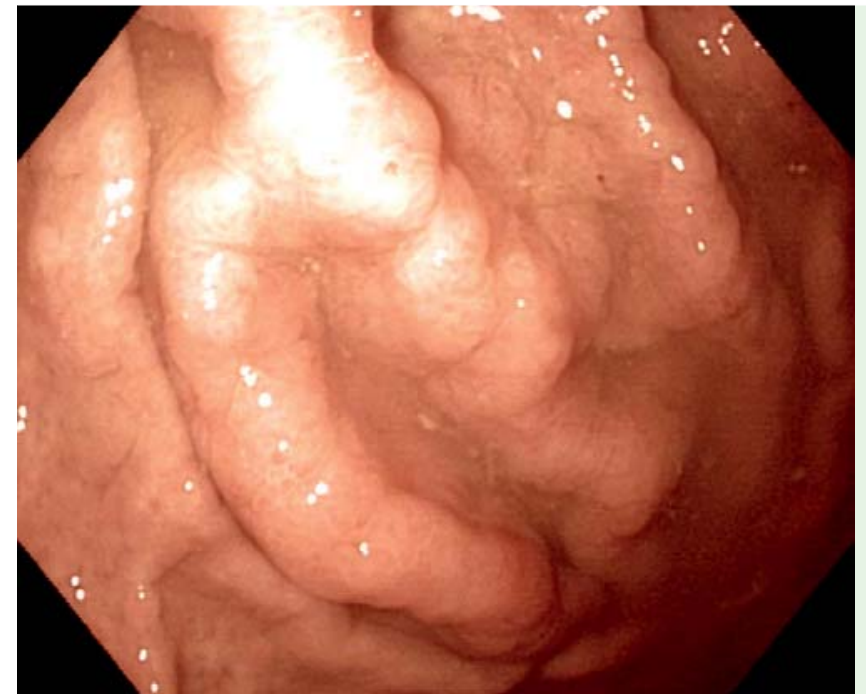

Fig. 1 Hypertrophic folds arising within the upper third of the stomach.

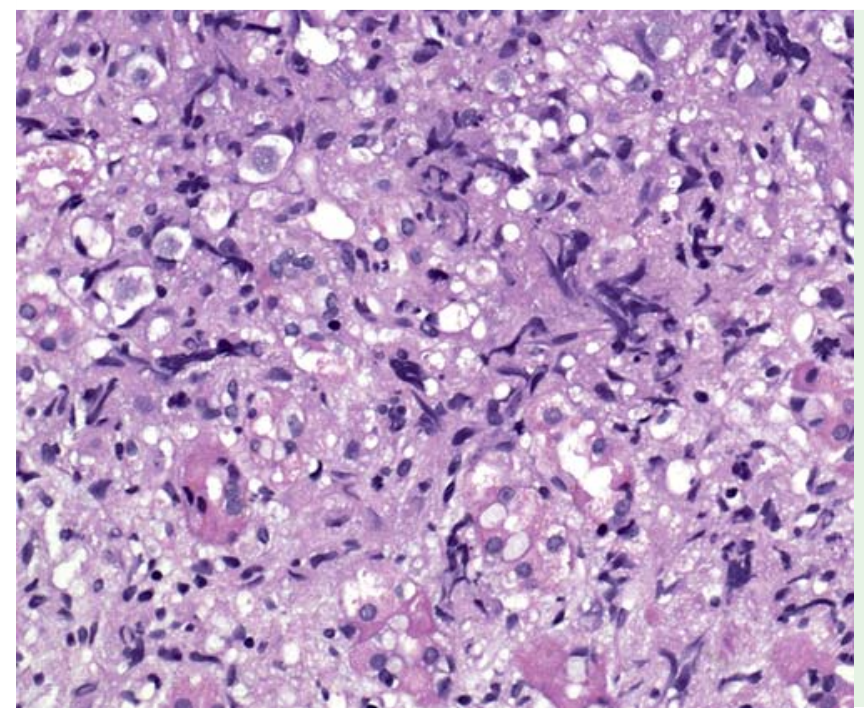

Fig. 2 Polymorphous cancer cells diffusely infiltrating gastric oxyntic-type mucosa.

Endoscopy_UCTN_Code_CCL_1AB_2AD_3AB

\section{References}

Competing interests: None

1 Oda I, Kondo H, Yamao T et al. Metastatic tumors to the stomach: analysis of 54 patients diagnosed at endoscopy and 347 autopsy cases. Endoscopy 2001; 33: 507-510

2 Holderman WH, Jacques JM, Blackstone MO et al. Prostate cancer metastatic to the stomach: clinical aspects and endoscopic diagnosis. J Clin Gastroenterol 1992; 14: 251 -254

3 Christoph F, Grünbaum M, Wolkers $F$ et al. Prostate cancer metastatic to the stomach. Urology 2004; 63: 778-779

4 Onitilo AA, Engel J, Resnick JM. Prostate carcinoma metastatic to the stomach: report of two cases and review of the literature. Clin Med Res 2010; 8: 18-21

5 Whitty LA, Crawford DL, Woodland JH et al. Metastatic breast cancer presenting as linitis plastica of the stomach. Gastric Cancer 2005; 8: 193-197 


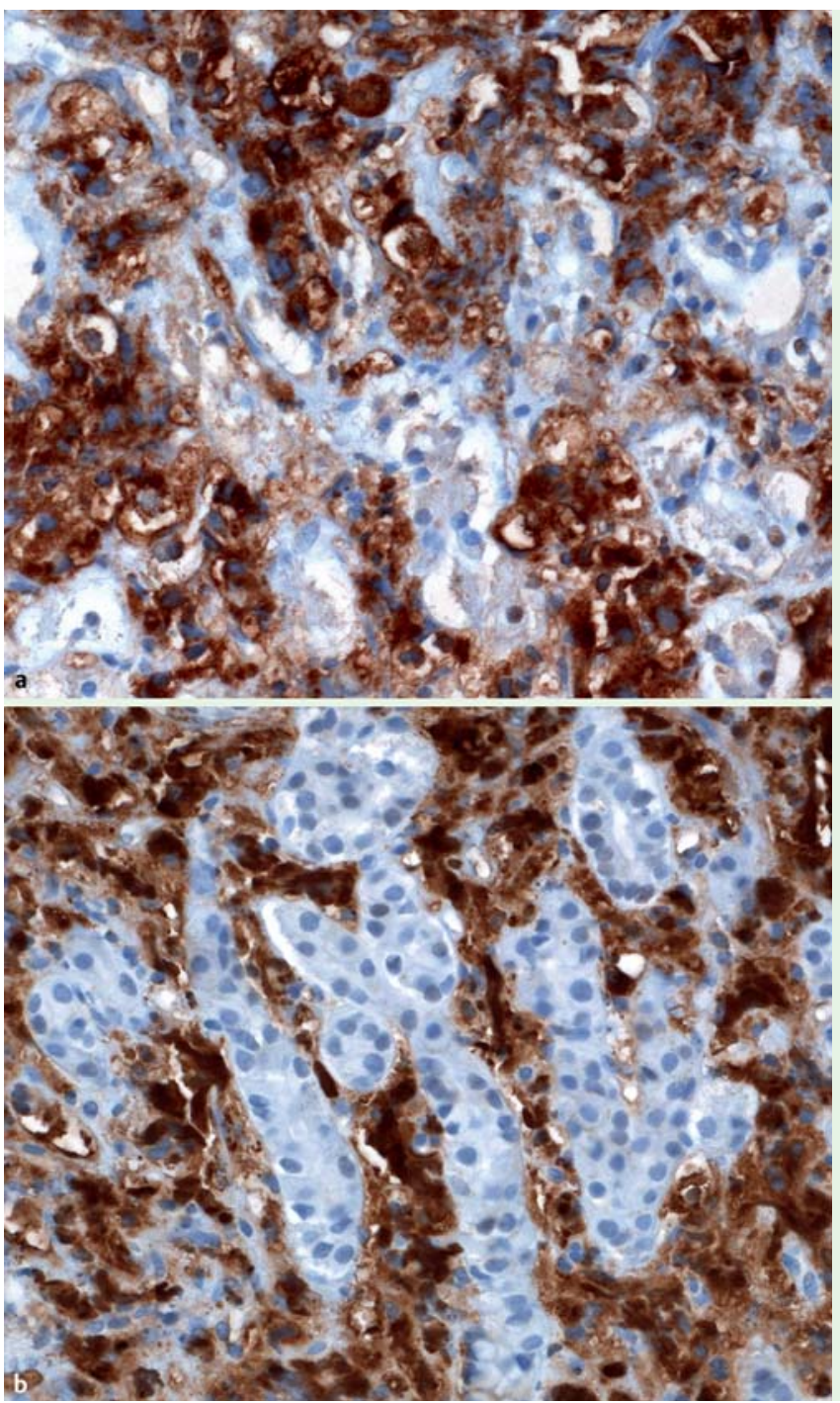

Fig. 3 The cancer cells are immunoreactive for: a prostate-specific antigen (PSA) and b androgen receptor.

\section{Bibliography}

Dol http://dx.doi.org/

10.1055/s-0031-1291524

Endoscopy 2012; 44: E47-E48

(c) Georg Thieme Verlag KG

Stuttgart · New York

ISSN 0013-726X

\section{Corresponding author}

\section{Langner, MD}

Institute of Pathology Medical University of Graz

Auenbruggerplatz 25

A-8036 Graz

Austria

Fax: +43-316-38513432

cord.langner@medunigraz.at 